\author{
A. Niedzielska", P. Skwierczyński, M. Czerniak-Reczulska, W. Szymański \\ Lodz University of Technology, Faculty of Mechanical Engineering, Institute of Materials \\ Science and Engineering, 90-924 Łódź, Stefanowskiego 1/15 Poland \\ *agata.niedzielska@p.lodz.pl
}

\title{
THE INFLUENCE OF THE RF PACVD MS PROCESS PARAMETERS ON THE PHYSICOCHEMICAL PROPERTIES OF HYDROXYAPATITE COATINGS
}

\begin{abstract}
Hydroksyapatite (HAp) as the coating, is produced using different methods of deposition, among others: laser ablation method, sol-gel, electrophoresis, thermal sputtering or magnetron spraying with the usage of high frequency. Attempts to benefit from such a wide spectrum of existing methods are related to the fact that this material possesses many advantages. We have to distinguish, among others, proper biological properties, i.e. both - high bio-tolerance and high osteo-inductivity [1,2]. However, it is worth mentioning that the material also presents disadvantages, i.e. it indicates too quick resorption within the biological environment, depending on its obtained form. In case when HAp is in the amorphous form, it undergoes a very rapid process of dissolving in the tissue environment. [3] In order to prevent the above, it is important to produce the coatings with a regulative level of cristallinity. In the presented research the hydroxyapatite coating produced using RF PACVD MS plasma method (Radio Frequency Plasma Assisted Chemical Vapor Deposition Magnetron Sputtering) possesses the above mentioned amorphous form. Nevertheless, due to the usage of 'bubbler', allowing for delivery of hydroxyl groups into the operating chamber, it was possible to receive the Hap coatings in a crystalline form. Changing the operating pressure (the amount of bonds $-\mathrm{OH}$ ), during sputtering, it was checked what is the influence of that parameter on the physicochemical properties of obtained coatings. Scanning electron microscopy (SEM) was used for the founding research as well as the Roentgen Apparatus Analyser (EDS). The Phase composition of a created coating was researched using the Roentgen diffract-meter (XRD). The measures of thickness were conducted using contact-profilometry. Nano-indentation technique was used to assess the mechanical properties. Obtained results of research encourage for further researches related to the influence of hydroxyl groups on the physicochemical properties of hydroxyapatat coatings.
\end{abstract}

Keywords: magnetron sputtering, hydroxyapatite, coating, radio frequency, water vapour

\section{INTRODUCTION}

Ageing population, life style, sport or communication injuries are the most common reasons for a constantly growing demand to replace the anatomic structures of organisms. Changes in bone-structures and articular injuries are the most commonly occurred and they need to be supplied. For that reason, there is a big interest within various Research Institutes and medical companies to design and produce biomaterials, characterised by appropriate mechanical, chemical properties as well as the geometrical structure of the surface. 
Engineering science of biomaterials surface, among others, aims at producing coatings basing on calcium and phosphor on both metal and non-metal foundations, provided to be applied for implants which can carry loads. Coatings reach in calcium and phosphor compounds should be existing in such circumstances where osteo-integration is required: in prostheses of hip or knee joints as well as dental implants. One of materials containing those chemical elements is hydroxyapatite (Hap) - $\mathrm{Ca}_{10}\left(\mathrm{PO}_{4}\right)_{6}(\mathrm{OH})_{2}$ which can be created using a wide spectrum of methods, among others: laser ablation, zol-gel, electrophoresis, thermal spraying and magnetron sputtering. Being a natural component of bone tissues, hydroxyapatite has been widely used in medicine, among others, considering its high bio-tolerance within the tissue environment as well as its high activity of that bio-material (stimulation of skeletonconstructive for height) [1, 2]. Moreover, Hap possesses certain disadvantages based on exposing too rapid resorption within the biological environment [3, 4]. In order to prevent from the above, it is important to create coatings of a regulated level of crystalline. Hydroxyapatite coating produced up till now in the Technical University of Łódź using RF PACVD MS plasma method (Radio Frequency Plasma Assisted Chemical Vapour Deposition Magnetron Sputtering) possesses the amorphic form [5]. At present, research is being conducted aiming at undertaking the trial to obtain the crystalline effect of the coating with the usage of the above mentioned plasma method $[6,7]$.

During plasma discharge into the operating chamber, hydroxyl groups $(-\mathrm{OH})$ were applied. Those groups are responsible for processes propagating to obtain crystalline hydroxyapatite coatings. The influence of hydroxyl groups on properties of obtained Hap coatings was presented in this work. In order to research the created coatings, Scanning Electron Microscopy (SEM) was used as well as Roentgen Analyser (EDS). The phase contents of a created coating were researched using a Roentgen diffract-meter (XRD). Measures of thickness were conducted using the contact profilometry. The nano-indentation technique was used to estimate the mechanical properties.

\section{EXPERIMENTAL}

Hydroxyapatite coatings were produced on two-phases Ti6Al7Nb titan alloy. Samples of $20 \mathrm{~mm}$ diameter and $5 \mathrm{~mm}$ high were used for the research. Before the process of vapour deposition process - the foundations underwent the grinding processing onto the abrasive paper of a decreasing gradation of granules: 120,320,600, 800, 1200, 2400, and then they underwent the polishing processing using the colloidal silica suspension base (SPM Presi), using an automatic polisher MECATECH 334 (Presi, France). The following step was based on cleaning the samples in methanol with the usage of ultrasound washer during 10 minutes. Coatings were produced in the chamber presented in Fig. 1, using RF PACVD MS method, in compliance with the parameters indicated in the Table 1. Research of the surface morphology as well as the quality establishment of the chemical composition of the coatings were conducted using the Hitachi S-300 N electron scanning microscope, equipped with the Thermo Noran Roentgen analyzer. The phase-composition of the HAp created coating was researched on he Roentgen diffract-meter SIEMENS D-500 with the usage of (Co $\left.\mathrm{K}_{\alpha}\right)$ cobalt lamp. The research was conducted with the step method, using the step $\Delta 2 \theta=0,05$ deg and the accounting time of 4 seconds. Electron beam current amounted to $40 \mathrm{~mA}$ while the voltage amounted to $30 \mathrm{kV}$. The measures of the obtained coatings thickness were performed using the Hommel Tester T1000 profile measurement gauge. The measurement of mechanical 
properties of the obtained coatings was done using the nano-indentation technique, with the usage of G200 (MTS Nano Instruments) the nano-intender. For the adhesion measure the method of the standard scratch was used, including the measure of the lateral force as well as the possibility to observe the intersection of the crosswise caving (Standard Scratch with Cross Profile and Lateral Force). The measure of the lateral force in the X-Y plane allows estimating the $\mu$ friction indicator. Basing on the changes of the friction indicator, penetration curves as well as observation with the usage of optic microscope the critical force of delamination $(\mathrm{Fc})$ could be defined. In order to establish $\mathrm{Fc}$ five scratches with a diamond cone of the vertex angle $90^{\circ}$ and the fillet radius $<1 \mu \mathrm{m}$ were done (for each sample). The force was linearly increasing within the range from $0 \mathrm{mN}$ to $50 \mathrm{mN}$.

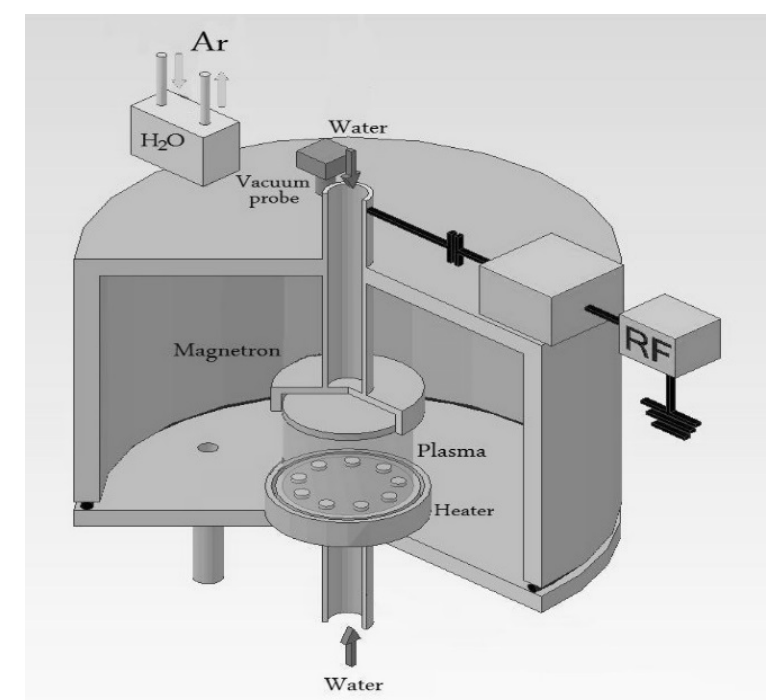

Fig. 1. Diagram of a device for hydroxyapatite layers deposition

Table 1. Deposition parameters of HAp films

\begin{tabular}{|c|c|c|c|c|c|c|}
\hline $\begin{array}{c}\text { Type of } \\
\text { gas }\end{array}$ & $\begin{array}{c}\text { Flow } \\
{[\mathrm{sccm}]}\end{array}$ & $\begin{array}{c}\text { Pressure } \\
{[\mathrm{Pa}]}\end{array}$ & $\begin{array}{c}\text { Application time } \\
{[\mathrm{min}]}\end{array}$ & $\begin{array}{c}\text { Power } \\
{[\mathrm{W}]}\end{array}$ & $\begin{array}{c}\text { Auto-polarity } \\
\text { voltage }[\mathrm{V}]\end{array}$ & $\begin{array}{c}\text { Substrate } \\
\text { temperature }\left[{ }^{\circ} \mathrm{C}\right]\end{array}$ \\
\hline $\mathrm{Ar}+\mathrm{H}_{2} \mathrm{O}$ & $15 \div 30$ & $1,5 \div 10$ & 600 & 200 & $740-840$ & 400 \\
\hline $\mathrm{Ar}$ & 20 & 2 & 600 & 200 & 800 & 400 \\
\hline
\end{tabular}

\section{RESULTS AND DISCUSSION}

Research results of the scanning microscopy with the analysis of the chemical composition are presented in Fig. 2. Comparing the research results with EDS it was stated that obtained coatings include calcium and phosphor in both cases. Basing on the intensity of peaks derived from the foundation we can say that the o obtained coating is thicker if argon is delivered to the operating chamber (Fig 4a). 


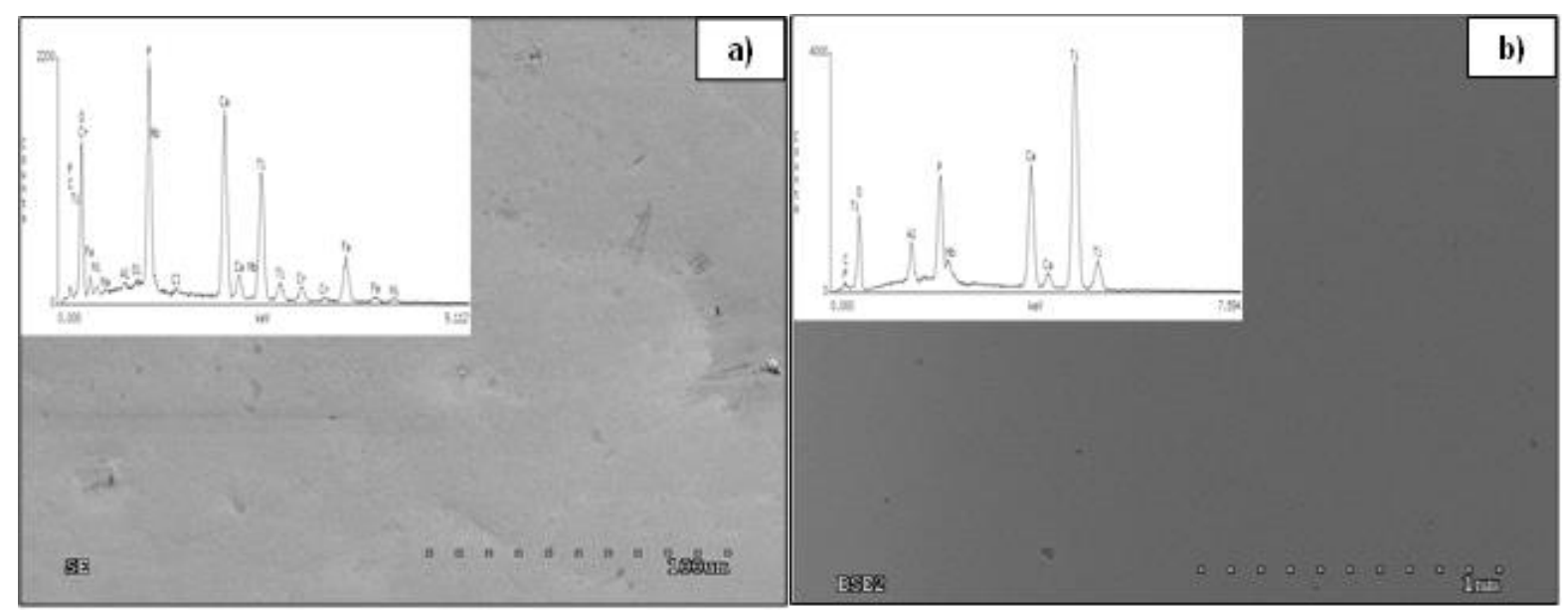

Fig. 2. Results of SEM and EDS analysis of the hydroxyapatite coatings for the working atmosphere: a) $\mathrm{Ar}, \mathrm{b}) \mathrm{Ar}+\mathrm{H} 2 \mathrm{O}$ at gas flow rate $20 \mathrm{sccm}$.

Research results of the Roentgen diffraction explicitly state that obtained coatings are in an amorphic form. However, the presence of a slight peak derived from a hydroxyapatite coating was only observed in Fig. 3c, confirmed by some research works F. Ozeka and Z. Hong [4, 8]. Presence of peak in those scope of angles testifies that there are crystalline areas present in the coating, in the amorphic matrix. The rest of visible, remaining peaks are derived from the foundation (titan alloy Ti6Al7Nb) what is confirmed by covering all the remaining peaks from the Fig. 3a, including $3 \mathrm{~b}$ and $3 \mathrm{c}$.

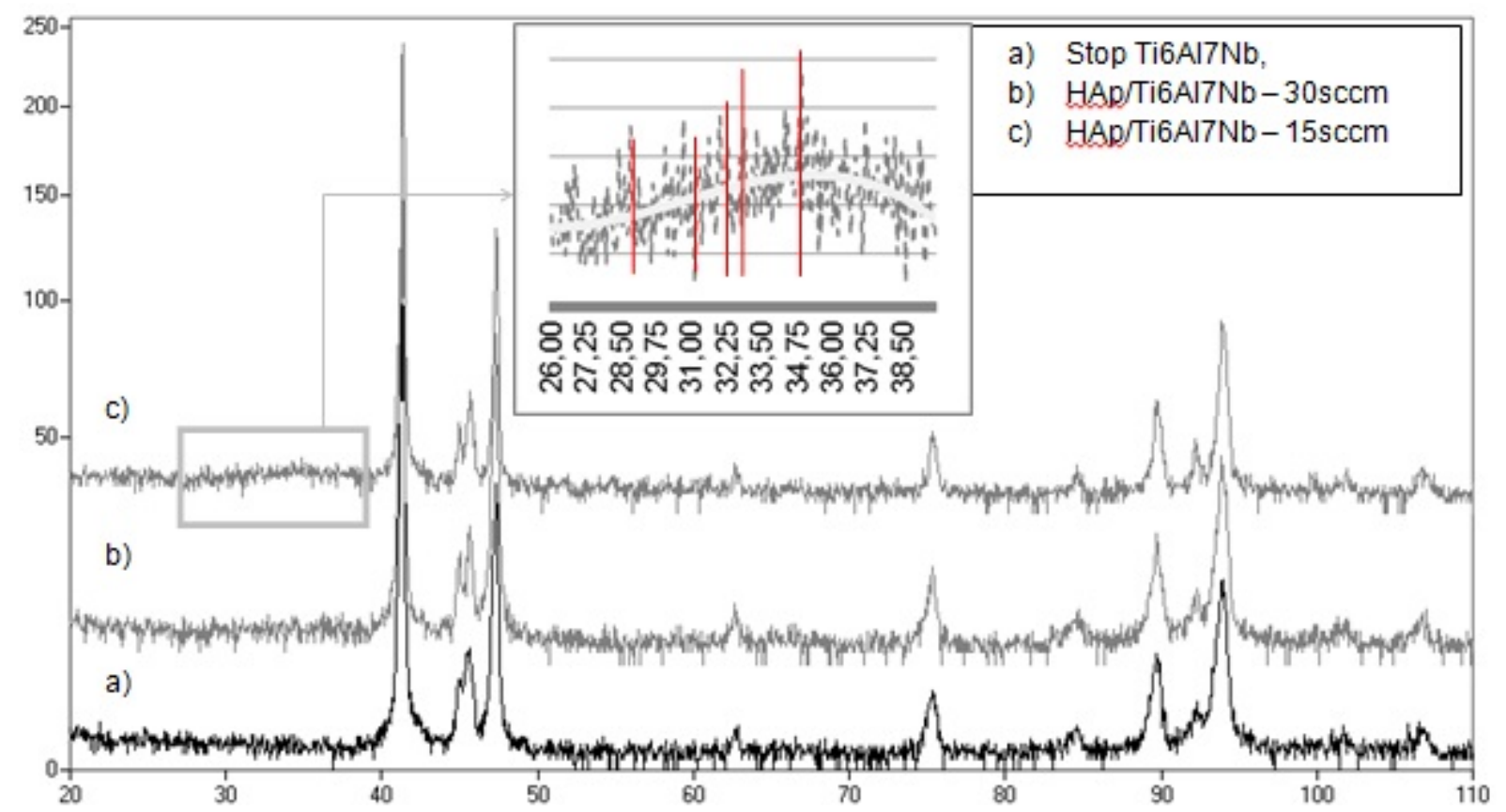

Fig. 3. The results of phase composition (XRD) of the substrate and the hydroxyapatite coating for: a) Ti6Al7Nb substrate and for the HAp coatings obtained at gas flow rate b) $30 \mathrm{sccm}$ and c) $15 \mathrm{sccm}$

Additionally, it can be formulated basing on the research thickness measures (Fig. 4) that if the amount of accessed operating gas to the chamber is increased then we can observe its decrease (Fig. 4b). A bigger amount of gas in the chamber, during the conduct of the process results in increase of the working pressure, which, in the end, may influence the decrease of the intensity of sputtering of hydroxyapatite cathode. 


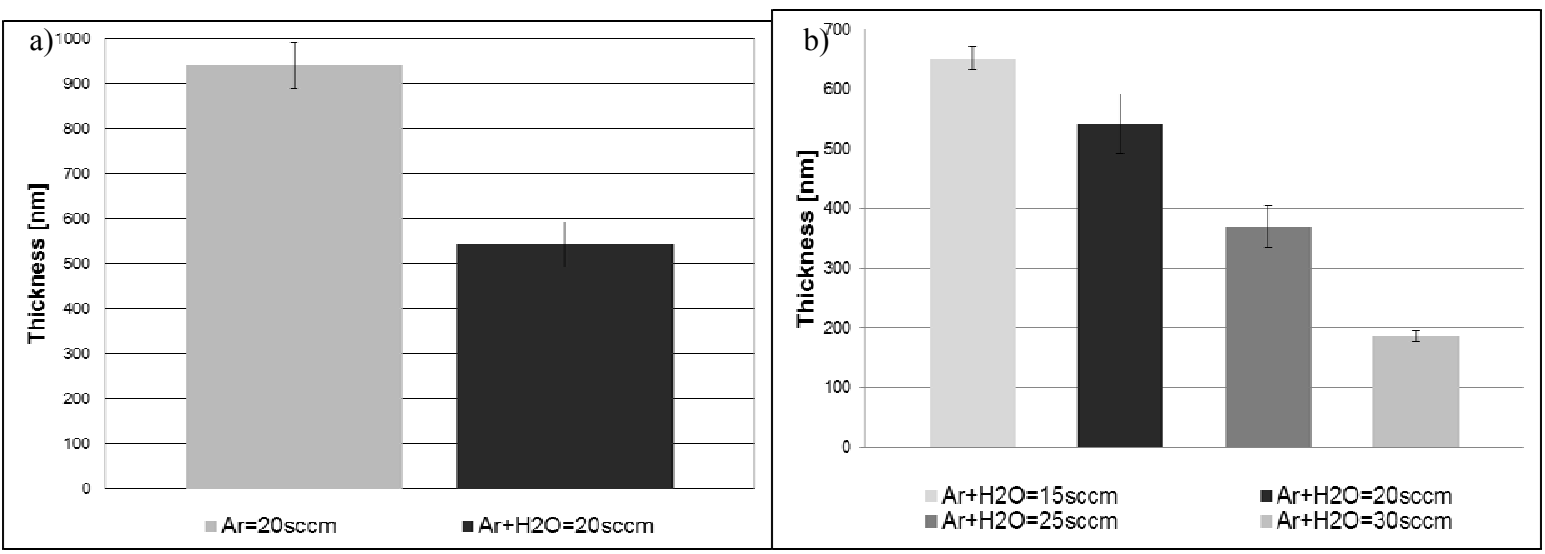

Fig. 4. The thicknesses measurement results of hydroxyapatite films: a) for different working atmosphere, b) for various gas flow

a)

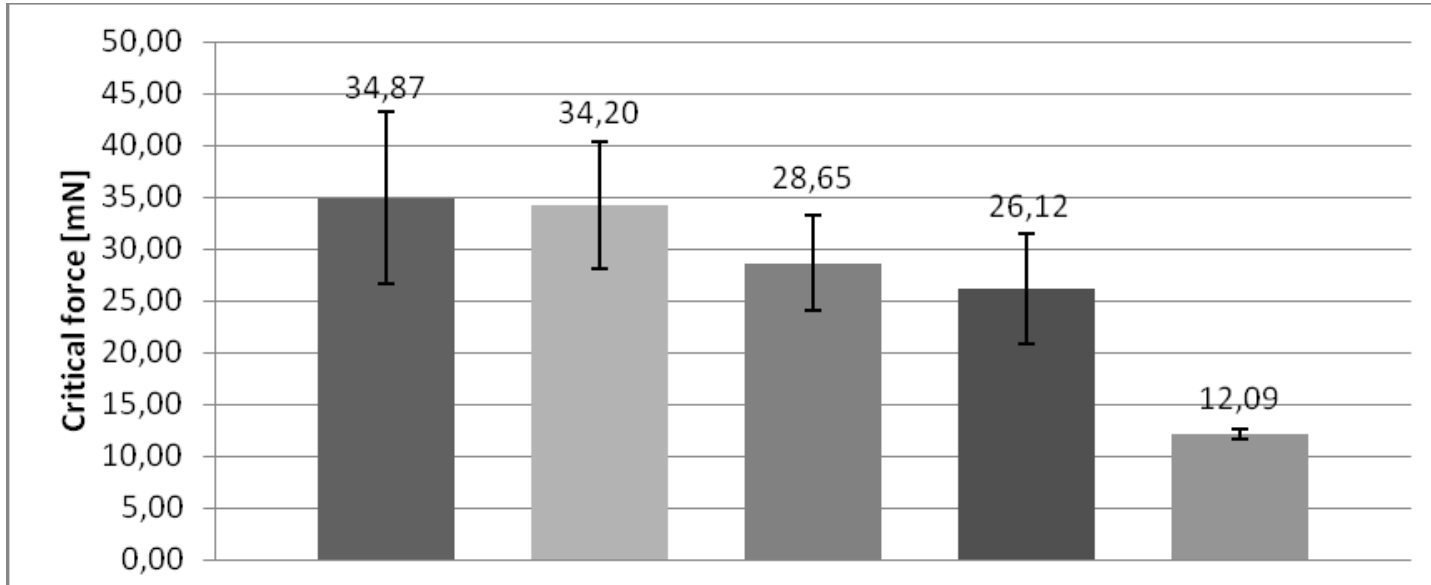

$\square \mathrm{Ar}+\mathrm{H} 2 \mathrm{O}=15 \mathrm{sccm} \square \mathrm{Ar}+\mathrm{H} 2 \mathrm{O}=20 \mathrm{sccm} \square \mathrm{Ar}+\mathrm{H} 2 \mathrm{O}=25 \mathrm{sccm} \square \mathrm{Ar}+\mathrm{H} 2 \mathrm{O}=30 \mathrm{sccm} \square \mathrm{Ar}=2 \mathrm{sccm}$

b)

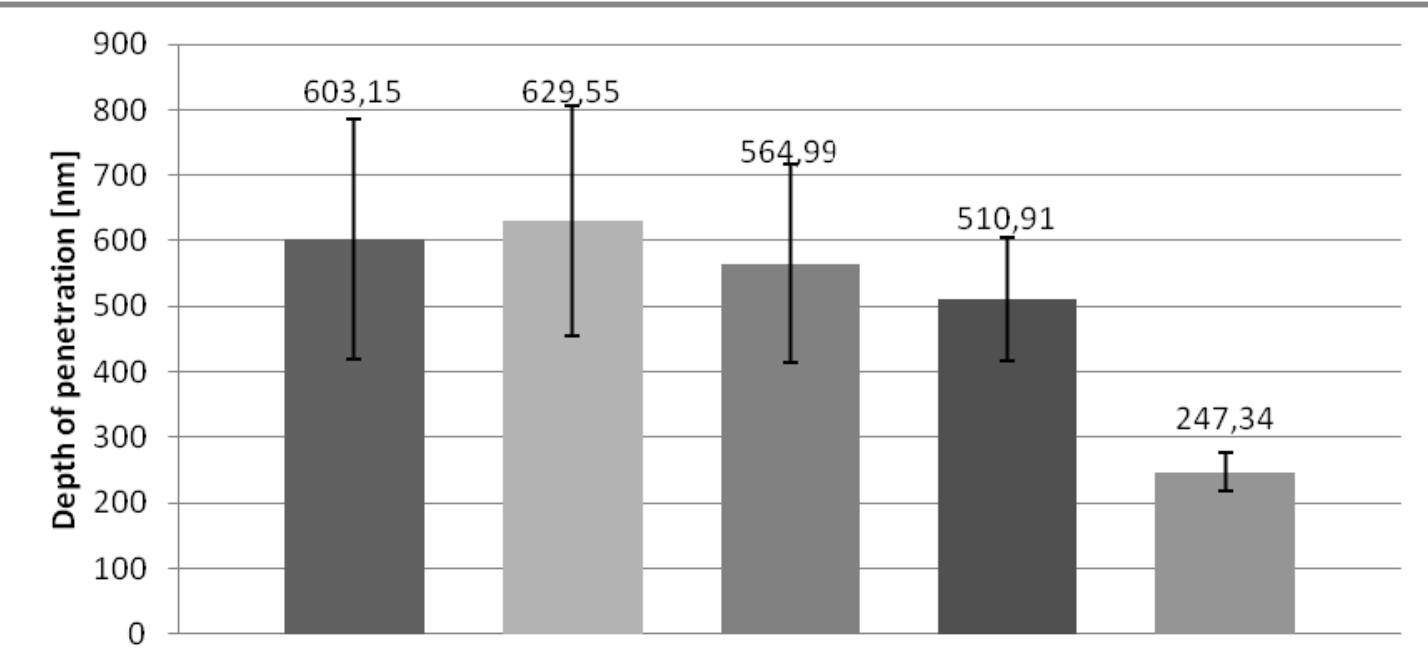

$\square \mathrm{Ar}+\mathrm{H} 2 \mathrm{O}=15 \mathrm{sccm} \square \mathrm{Ar}+\mathrm{H} 2 \mathrm{O}=20 \mathrm{sccm} \square \mathrm{Ar}+\mathrm{H} 2 \mathrm{O}=25 \mathrm{sccm} \quad \mathrm{Ar}+\mathrm{H} 2 \mathrm{O}=30 \mathrm{sccm} \square \mathrm{Ar}=20 \mathrm{sccm}$

Fig. 5. The measurement results of adhesion by scratch-test method using nanoindentation: a) critical force, b) the depth of penetration 
Results of adhesion made using the scratch-test method are presented on Fig. 5. Increase of the coatings adhesion occurs simultaneously with the realise of gases including hydroxyl groups into the chamber. Critical force for the hydroxyapatite, produced in the presence of a pure argon, amounts to $12,09 \pm 0,43 \mathrm{mN}$, while for the obtained coating at the lowest flow of argon $-(15 \mathrm{sccm})$, with an addition of the hydroxyl groups $(-\mathrm{OH})$ amounts to $34,87 \pm 8,31 \mathrm{mN}$, and, at the same, it significantly improves that parameter - increasing it almost for three times. Further increase of those groups concentration through the increase of argon flow is decreasing the value of the critical force - adequately: $34,20 \pm 6,14 \mathrm{mN}$ for $20 \mathrm{sccm}$, $28,65 \pm 4,54 \mathrm{mN}$ for $25 \mathrm{sccm}$ and $26,12 \pm 5,30 \mathrm{mN}$ for $30 \mathrm{sccm}$.

Photos of chosen scratches provided from the scratch-test research are presented in Fig. 6. The features of tearing off the coatings from the covered foundations is identical for all speeds of the operating gas flow, including the hydroxyl groups. Moreover, we observe the fact where there is an increase of the gas flow the coating is cut even at the lowest load, confirmed by the results obtained from the measurement of the critical force.
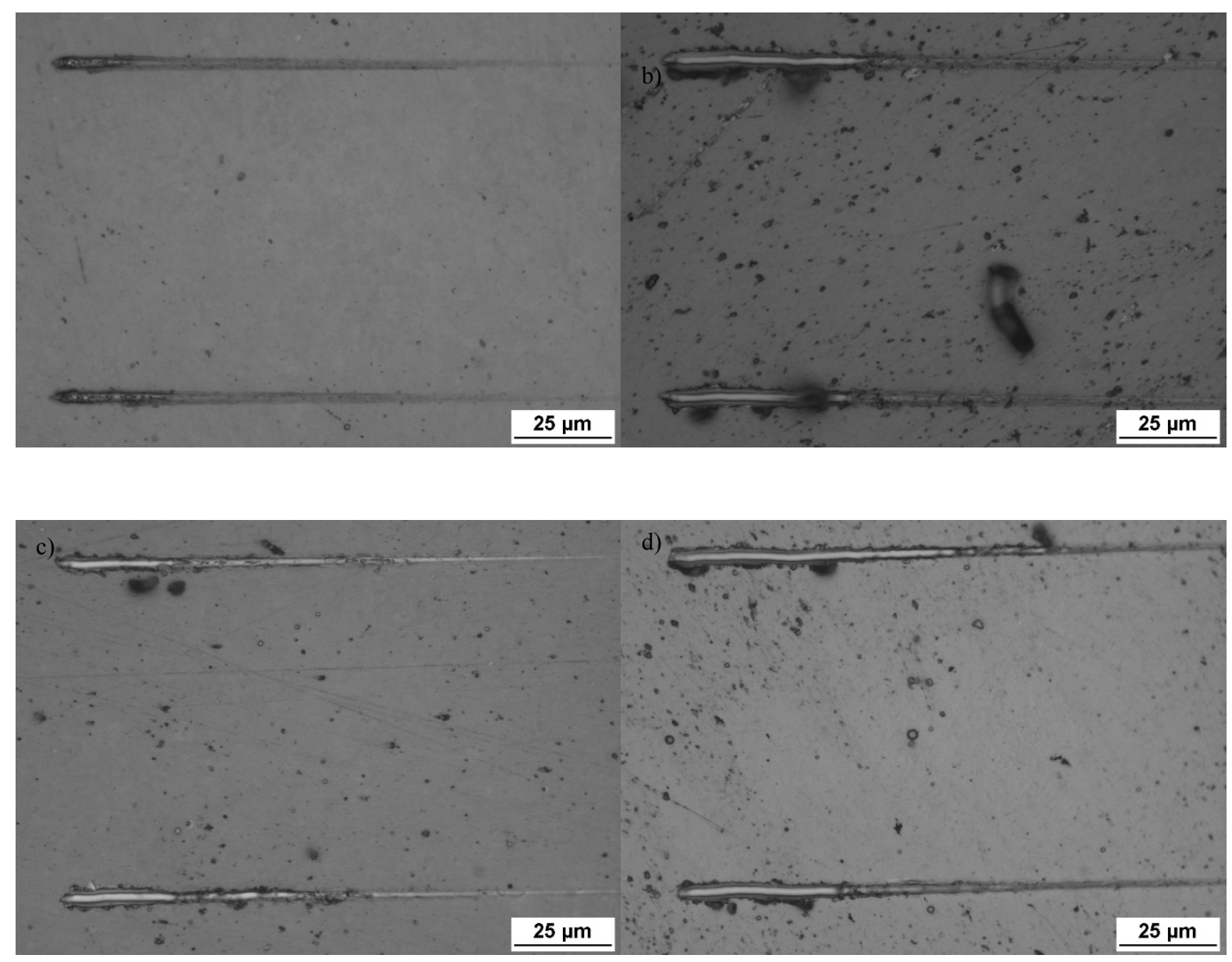

Fig. 6. Images of the wear tracks after scratch-test for coatings obtained for gas flow rate containing hydroxyl groups: a) $15 \mathrm{sccm}$, b) $20 \mathrm{sccm}, \mathrm{c}) 25 \mathrm{sccm}$, d) $30 \mathrm{sccm}$ 


\section{CONCLUSIONS}

Conducted research using the scanning microscopy method (SEM) showed that obtained coatings are homogenous for the following: operating atmosphere consisted of pure argon, argon and gases including the hydroxyl groups $(-\mathrm{OH})$. Coatings obtained using the magnetron spraying with a generator of the radio frequency indicate the amorphic form, confirmed by the research results of Roentgen diffraction (XRD). For the coating produced for the gas flow of $15 \mathrm{sccm}$ the coating with the crystalline areas in the amorphic matrix was obtained. Moreover, it was observed that the introduction of the hydroxyl groups $(-\mathrm{OH})$ into the operating chamber significantly influenced the improvement of adhesion of the obtained coatings - the critical force $(\mathrm{Fc})$ was increased for three times, where the coating can be cut. Obtained results of the research encourage for conducting further works related to the influence of hydroxyl groups on the physic-chemical properties as well as on the form of hydroxyapatite coatings.

\section{REFERENCES}

1. Batory D., Gawroński J., Kaczorowski W., Niedzielska A., C - HAp composite layers deposited onto AISI 316 L austenitic steel. Surf. Coat. Technol. 206(8-9) (2012), 2110.

2. Gawroński J.: Wytwarzanie kompozytowych warstw C/HAp na potrzeby medycyny. (Preparation of composite layers C / HA p for the purposes of medicine) PhD thesis, Lodz University of Technology, Lodz (2008).

3. Wolke J.G.C., De Groot K., Jansen J.A.: Dissolution and adhesion behaviour of radio-frequency magnetron-sputtered Ca-P coatings. J. Mater. Sci. 33(13) (1998), 3371.

4. Ozeki K., Aoki H., Fukui Y.: Dissolution behavior and in vitro evaluation of sputtered hydroxyapatite films subject to a low temperature hydrothermal treatment. J. Biomed. Mater. Res. Part A, 76A (3) (2006), 605.

5. Walkowiak-Przybyło M., Okrój W., Walczyńska M., Skwierczyński P., Walkowiak B.: Thrombogenicity of thin layer calcium phosphate created on polished surface of Ti6Al7 $\mathrm{Nb}$ alloy Eng of Biomater, Vol XIV (109-11), 37, (2011).

6. Fernandez-Pradas J.M., Cleries L., Martinez E., Sardin G., Esteve J., Morenza J.L.: Calcium phosphate coatings deposited by laser ablation at $355 \mathrm{~nm}$ under different substrate temperatures and water vapour pressures. Appl. Phys. Mater. Sci. Process. 71(1) (2000), 37.

7. Kim H., Camata R.P., Vohra Y.K., Lacefield W.R.: Control of phase composition in hydroxyapatite-tetracalcium phosphate biphasic thin coatings for biomedical applications. $\mathrm{J}$ Mater Sci Mater Med., 16 (10) (2005),961.

8. Hong Z., Luan L., Paik S., Deng B., Ellis D.E., Ketterson J.B., Mello A., Eon J.G., Terra J., Rossi A.: Crystalline hydroxyapatite thin films produced at room temperature - An opposing radio frequency magnetron sputtering approach Thin Solid Films 515 (2007), 6773. 